\title{
Case Report: Sponteneous Esophageal Pleural Fistula
}

\section{Ashish Deshmukh*, Sunil Jadhav, Shivprasad Kasat, Hafiz Deshmukh, Chintan Yadav and Saumya Ramachandran}

Department of Pulmonary Medicine, MGM Medical College, Aurangabad, Maharashtra, India

\begin{abstract}
We are reporting a rare case of spontaneous esophageal-pleural fistula in a middle aged male patient who was presented with chest pain, breathlessness on minimal exertion, dry cough, fever. Chest $x$ ray was done which is suggestive of hydro pneumothorax, so intercostal drain was inserted which drained frank pus. His CECT Chest done which showed fistulous track between esophagus and pleural with mediastinitis. Patient was diagnosed as a case of spontaneous esophageal pleural fistula on above mentioned background. Patient was referred to cardio thoracic surgeon for further management.
\end{abstract}

\section{Introduction}

Esophageal pleural fistula is a rare condition which is occurred secondary to esophageal surgery, instrumentation, malignancy or a rare pneumenectomy complication [1-7]. Very rarely spontaneous esophageal pleural fistula has been reported. We are reporting a case of a patient who was initially diagnosed as a pyopneumothorax and started on anti-tubercular treatment empirically. His contrast enhanced computed tomography was done s/o esophageal pleural fistula. Contrast enhanced Computed tomography is useful in evaluation of esophageal pleural fistula1. A case report with brief review of radiological findings and management of EPF has been discussed.

\section{Case Report}

45 years male patient before presenting to our hospital, admitted in other private hospital with complaints of sudden onset of chest pain, breathlessness on minimal exertion, high grade fever and dry cough since 7 days. No complaints of abdominal pain, vomiting. He was diagnosed as having left sided hydropneumothorax on the basis of chest $\mathrm{x}$ ray frontal view. He was inserted left sided intercostal drain and it drained around $300 \mathrm{ml}$ of frank pus. Patient was started on anti-tubercular treatment empirically and he was discharged with chest tube in situ on left side. After 3 days patient presented in emergency department with accidental removal of intercostal drain. On examination patient was conscious and oriented, febrile (101 F), his pulse rate was $120 /$ minute and Blood pressure was 100/70 $\mathrm{mm} \mathrm{Hg}$. His respiratory rate was $24 /$ minute and oxygen saturation at room air was $92 \%$. On inspection his chest movement was diminished on left side. On auscultation breath sounds are absent in left side of lung field. Chest radiograph (Figure 1) showed left sided hydropnemothorax. Left sided intercostal drain was inserted which drained $1200 \mathrm{ml}$ of frank pus. His blood reports were done. It showed leukocytosis (total WBC count: 16,100). His liver function test, kidney function test, random blood sugar, serum electrolytes were within normal limits. Serology was negative for HIV antibody. His pleural fluid reports showed protein $3.3 \mathrm{gm} / \mathrm{dl}$, glucose $13 \mathrm{mg} / \mathrm{dl}$, ADA $60.1 \mathrm{U} / \mathrm{L}, \mathrm{LDH} 4031 \mathrm{U} / \mathrm{L}$, total cell counts were $4000 / \mathrm{cu} \mathrm{mm}$ with neutrophils $90 \%$ and lymphocytes $10 \%$. His Contrast enhanced computed tomography (Figure 2) was done which showed fistulous tract between thoracic esophageal and left pleural cavity and resultant pyopneumothorax, multiple enlarged reactive mediastinal lymph nodes were seen with signs of mediastinitis with minimal loculated right sided pleural effusion. So in the absence any evident cause for esophageal perforation patient was diagnosed as a case of spontaneous esophageal pleural fistula presented as left sided pyopneumothorax with mediastinitis. Patient was then referred to cardio-thoracic surgeon for further management and treatment.

\section{Discussion}

Esophageal pleural fistula is a rare condition, but represents one of the more common complications of esophageal perforation. Anatomically, the esophagus is in direct contact with the lung pleura for a considerable distance on the right side, whereas on the left side, the aorta lies in between the esophagus and the pleura, except for a short distance just above the diaphragm. Therefore, processes in the esophagus can spread more easily into the right side of pleura rather than the left [8], In our case, perforation occurred on left side which is a very rare presentation.

Esophageal fistula is usually an acquired lesion in adults and can occur as a complication of intrathoracic malignancies due to direct extension, but can also manifest as a complication of esophageal tuberculosis, surgical procedures, and therapeutic interventions such as biopsy, dilatation, hemostasis, stent placement, foreign body removal, cancer palliation, and endoscopic ablation techniques can also dramatically increase the risk of perforation. In patients with esophageal cancer, incidence of EP fistula is 5-15\% $[9,10]$.

Fistulae further lead to development of complication in the mediastinum, trachea-bronchial tree, pleura, and lung which includes mediastinitis, empyema, and aspiration pneumonia [11]. Because of the potentially high morbidity and mortality associated with these complications, early diagnosis with imaging is important. Untreated fistulae results in continued respiratory contamination, sepsis, and death. EP fistulas have a propensity to develop in extremely later stages of esophageal cancer, when remedial surgery is no longer considered.

Systemic antibiotics should be administered for at least 4-6 weeks for sterilization of the empyema cavity. Definitive management involves complete drainage of empyema and obliteration of empyema cavity by lung expansion that can be addressed following closure of EP fistula. Fistula can be closed with self-expanding metal stents or by surgical exploration with a muscle flap [12]. However, even with appropriate procedural intervention, prognosis is poor if the mediastinum is involved.

*Corresponding author: Ashish Deshmukh, Department of Pulmonary Medicine, MGM Medical College, Aurangabad, Maharashtra, India, Tel: 919545203836; E-mail: dr.Chintanyadav@gmail.com

Received March 30, 2015; Accepted April 22, 2015; Published April 27, 2015

Citation: Deshmukh A, Jadhav S, Kasat S, Deshmukh H, Yadav C, et al. (2015) Case Report: Sponteneous Esophageal Pleural Fistula. J Pulm Respir Med 5: 259 doi:10.4172/2161-105X.1000259

Copyright: (C) 2015 Deshmukh A, et al. This is an open-access article distributed under the terms of the Creative Commons Attribution License, which permits unrestricted use, distribution, and reproduction in any medium, provided the original author and source are credited. 


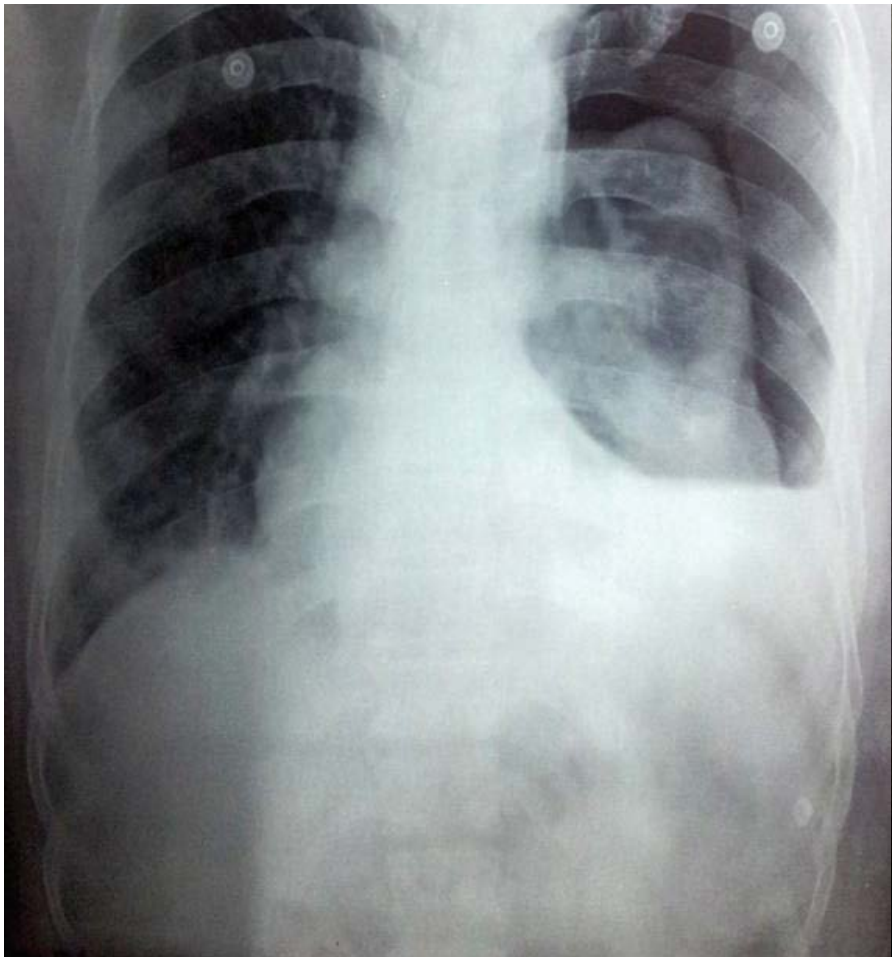

Figure 1: chest x-ray pa view showing left sided hydropneumothoxax.

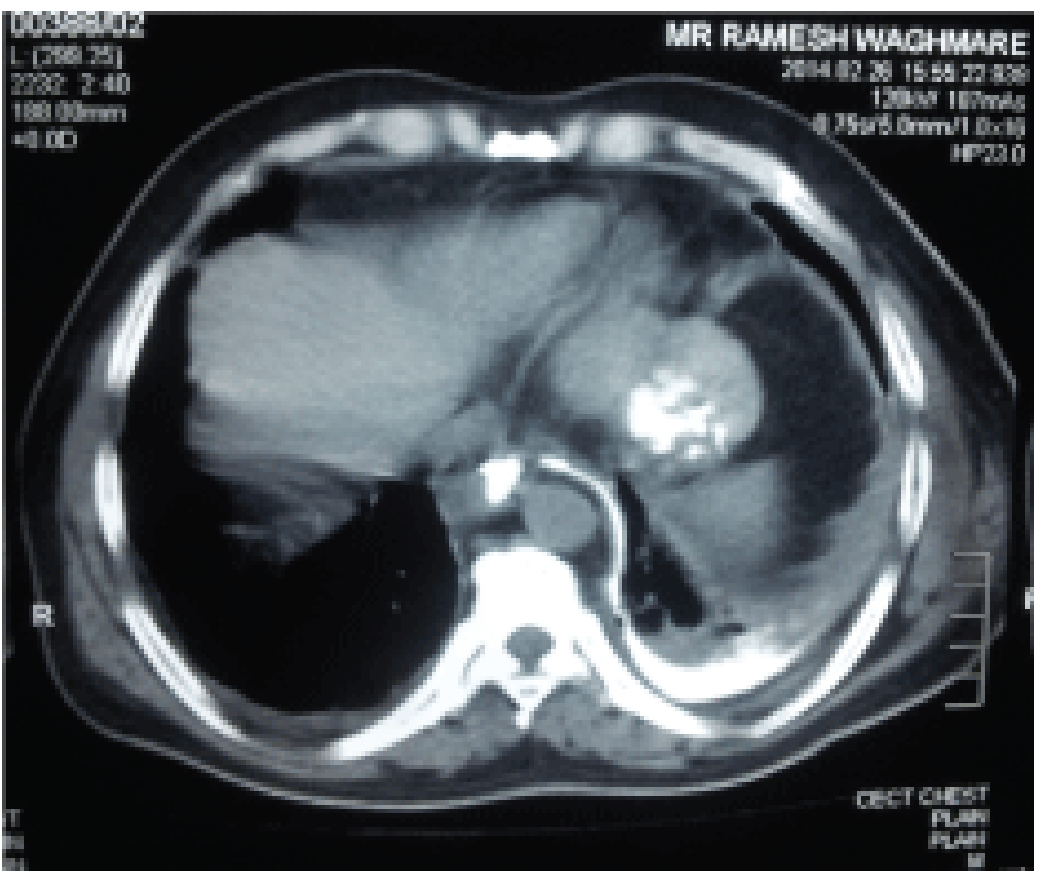

Figure 2: Axial section of computed tomography showed fistulous tract between thoracic esophagus and left pleural cavity with left sided pyopneumothorax and right sided minimal pleural effusion. 


\section{References}

1. Vyas S, Prakash M, Kaman L, Bhardwaj N, Khandelwal N (2011) Spontaneous esophageal-pleural fistula. Lung India 28: 300-302.

2. Wechsler RJ (1986) CT of esophageal-pleural fistulae. AJR Am J Roentgenol 147: 907-909.

3. Wechsler RJ, Steiner RM, Goodman LR, Teplick SK, Mapp E, et al. (1982) latrogenic esophageal-pleural fistula: subtlety of diagnosis in the absence of mediastinitis. Radiology 144: 239-243.

4. Liu PS, Levine MS, Torigian DA (2006) Esophagopleural fistula secondary to esophageal wall ballooning and thinning after pneumonectomy: findings on chest CT and esophagography. AJR Am J Roentgenol 186: 1627-1629.

5. Van Den Bosch JM, Swierenga J, Gelissen HJ, Laros CD (1980) Postpneumonectomy oesophagopleural fistula. Thorax 35: 865-868.

6. Al-Shawwa B, D'Andrea L, Quintero D (2008) Candida esophageal perforation and esophagopleural fistula: a case report. J Med Case Rep 2: 209.
7. Pache G, Thuerl C, Bley T, Kotter E, Ghanem N (2005) Asymptomatic esophagopleural fistula presenting 35 years after pneumonectomy for tuberculosis. $J$ Thorac Imaging 20: 223-225

8. Chuah BY, Khoo KL, Khor CJ (2008) Clinical challenges and images in GI Esophagopleural fistula. Gastroenterology 134: 919, 1275.

9. Duranceau A, Jamieson GG (1984) Malignant tracheoesophageal fistula. Ann Thorac Surg 37: 346-354.

10. Sarper A, Oz N, Cihangir C, Demircan A, Isin E (2003) The efficacy of selfexpanding metal stents for palliation of malignant esophageal strictures and fistulas. Eur J Cardiothorac Surg 23: 794-798.

11. Wechsler RJ (1986) CT of esophageal-pleural fistulae. AJR Am J Roentgenol 147: 907-909.

12. Cherveniakov A, Tzekov C, Grigorov GE, Cherveniakov P (1996) Acquired benign esophago-airway fistulas. Eur J Cardiothorac Surg 10: 713-716. 